\title{
PERLINDUNGAN TERHADAP PENCARI SUAKA DAN PENGUNGSI MENURUT HUKUM ISLAM DAN HUKUM INTERNASIONAL: (Studi Filosofis dan Ontologis Keilmuan) M. Alvi Syahrin*
}

\begin{abstract}
The problem of refugees and the displacement of people in the country is the most difficult problem facing the world community today. Many discussions were held at the United Nations which continued to seek more effective ways to protect and assist these very vulnerable groups. Some people call for increased cooperation and coordination between aid agencies, others point to gaps in international regulations and call for further standards in this field. However, everyone agrees that this problem is a global and global problem. Therefore every approach and solution must be carried out comprehensively and explain all aspects of the problem from the causes of mass exodus to the elaboration of the necessary responses to overcome the range of problems of refugees from emergencies to repatriation. This study will discuss how the basic rules of protection for asylum seekers and refugees according to Islamic law and international law.
\end{abstract}

Kata Kunci: Pencari Suaka, Pengungsi, Hukum Islam, Hukum Internasional.

Ajaran Islam tidak hanya berkaitan dengan persoalan keagamaan, tetapi juga dengan persoalan hari-hari keduniaan, termasuk persoalan hubungan antar individu, antar masyarakat, antar bangsa dan antar negara (Syahrin, 2014a, 2014d, 2014e). Karena itu tidaklah aneh apabila Islam hadir untuk menjelaskan segala sesuatu, baik itu urusan keagamaan maupun urusan muamalah (keduniaan). Ini ditegaskan oleh kalam Allah SWT: yang anrtinya: "dan Kami turunkan kepadamu Al kitab (al-Qur'an) untuk menjelaskan segala sesuatu. (Q.S. al-Nahl:89). Selanjutnya dalam Q.S. alNahl dijelaskan, yang artinya: dan Kami turunkan kepadamu al-Qur'an, agar kamu menerangkan pada umat manusia apa yang telah diturunkan kepada mereka dan supaya mereka memikirkan. (Q.S. al- Nahl:44). Kemudian dijelaskan dalam Q.S. al-Mâ'idah: 3yang artinya: pada hari ini telah Kusempurnakan untuk kamu agamamu, dan telah Ku-cukupkan kepadamu nikmat-Ku, dan telah Ku-ridhai Islam itu menjadi agama bagimu. (Q.S. alMâ'idah: 3)

Pengungsi dikualifikasi sebagai kelompok orang yang rentan (vulnerable persons). Seseorang dapat dikualifikasi sebagai pengungsi manakala: pertama; dalam konteks pertimbangan personal-individual, yakni seseorang yang lari mengungsi baik sendirian atau beserta keluarganya dari negaranya dimana ia dapat mengalami penindasan/penyiksaan ke negara tujuan tempat ia mencari suaka; kedua; sebagai bagian dari kelompok yang terusir/terasingkan akibat situasi dan kondisi politik, keagamaan, militer, atau lainnya, dimana ia menghadapi ancaman penindasan/ penyiksaan. (Syahrin, 2014b, 2015a, 2015b).

Pengungsi berbeda dari orang yang bermigrasi di wilayah negaranya

"Kepala Pusat Penelitian dan Pengabdian Masyarakat pada Politeknik Imigrasi, Kementerian Hukum dan Hak Asasi Manusia Republik Indonesia. Email:ma.syahrin@gmail.com. 
dan orang yang bermigrasi dengan motif ekonomi (migran ekonomi), atas dasar perbedaan sebagaiberikut:pertama; pengungsi adalah orang yang menyeberangi batas teritorial negara lain dengan maksud mencari perlindungan, rasa aman, dansuaka (Hashimoto, 2018); kedua; pengungsi dalam negeri (internally displaced person), tujuan mereka terkadang sama dengan tujuan pengungsi. Akan tetapi, mereka berbeda dari pengungsi luar negeri, terutama dari segi bahwa mereka tetap tinggal di wilayah negaranya sendiri dan memperoleh perlindungan yang harus diberikan kepada mereka sesuai dengan aturan hukum yang berlaku (Syahrin, 2016a, 2016b, 2016c).ketiga; migran ekonomi adalah orang yang meninggalkan negaranya secara sukarela dan bukan lantaran rasa takut akan penindasan/penyiksaan; melainkan lebih didasarkan pada motif ekonomi, demi peningkatan kesejahteraan hidupnya. Oleh karena itu, Deklarasi Negara-Negara Arab tentang Tenaga Buruh Migran Internasional yang diadopsi oleh Liga Arab pada tahun 2006 menghimbau pemerintah negara-negara Arab untuk membedakan secara intrinsik antara orang yang migrasi dan pengungsi yang masing-masing memiliki motivasi hak dan kebutuhan yangberbeda (Syahrin, 2017a, 2017b, 2017c, 2017d).

\section{Konsep Pengungsi dan Pencari Suaka Menurut Hukum Islam}

Di dalam bahasa Arab, kata al-malja' memiliki lebih dari satu arti. Di antaranya sebagai kata kerja, kata tersebut berarti "berlindung" seperti dalam ungkapan: "seseorang berlindung di benteng itu" (Syahrin, 2017e, 2017f, 2017g, 2017h). Maksudnya, ia berlindung dari hal yang membahayakan dengan tinggal/berada di dalam benteng itu. Sedangkan almalja' sebagai kata benda adalah tempat atau obyek yang dijadikan untuk berlindung dari halyang membahayakan, seperti benteng, gunung/bukit, dan goa. Arti ini muncul pada Q.S. al-Taubah ayat 57 yang artinya: jikalau mereka memperoleh tempat perlindunganmu atau gua- gua atau lobanglobang (dalam tanah) niscaya mereka segera pergi kepadanya dengan secepat-cepatnya. (Q.s. al-Taubah:57).

Kemudian dalam Q.S. al-Taubah: 118) yang artinya: dan terhadap tiga orang yang ditangguhkan (penerimaan taubat) mereka, hingga apabila bumi telah menjadi sempit bagi mereka, Padahal bumi itu luas dan jiwa merekapun telah sempit (pula terasa) oleh mereka, serta mereka telah mengetahui bahwa tidak ada tempat lari dari (siksa) Allah, kecuali kepada-Nya saja. Kemudian Allah menerima taubat mereka agar mereka tetap dalam taubatnya.Sesungguhnya Allah-lah yang Maha Penerima taubat lagi Maha Penyayang.(Q.S. alTaubah:118).

Selanjutnya dijelaskan dalam Q.S. al-Syura: 47 yang artinya: patuhilah (seruan) Tuhanmu sebelum datang dari Allah suatu hari yang tidak dapat ditolak kedatangannya. Kamu tidak memperoleh tempat berlindung pada hari itu dan tidak (pula) dapat mengingkari (dosa-dosamu). (Q.S. al-Syûra:47).

Di dalam pokok bahasan maśdar (kata benda), terdapat lebih dari satu bentuk mas dar dari asal satu kata kerja. Ibn Qutaibah mengatakan: “ âwaitu lahu ma'wiyah wa 'iyah, yang berarti menyayangi; serta âwaitu ila bani fulân âwan auyan; dan âwaitu fulân-an îwâ-an, yang berarti melindungi (Syahrin, 2017i, 2018a, 2018b, 2018c). Tak diragukan lagi, semua arti 
tersebut dapat diterapkan dalam hal pencarian dan pemberian suaka atas dasar pertimbangan bahwa sekiranya yang tampak itu makna "melindungi" maka makna ini pada intinya perluasan dari makna "menyayangi" pengungsi, dengan memperhatikan situasi dan kondisi yang mengitarinya (Syahrin, 2018d, 2018e, 2018f, 2018g, 2018h). Perlu dicatat bahwa bangsa Arab menggunakan kata "awaituhu" (saya memberikan suaka kepadanya) dengan pola kata kerja fa'altu (saya sudah memberikan perlindungan) dan af'altu (saya sudah memberikan perlindungan) untuk makna yang sama, tetapi terkadang mereka menggunakan ungkapan "âwaitu ila fulan" (aku memberi perlindungan kepadaseseorang) (El-Wafa, 2009).

Hak perlindungan diakui merupakan jiwa tradisi masyarakat Arab yang telah mengakar kuat, yang dilarang keras untuk dilanggar.Pemberian bantuan perlindungan kepada orang yang sangat membutuhkan merupakan perilaku mulia bangsa Arab dan umat Muslim (Hamid, 2012).Oleh karena itu, para pujangga Arab menyebut-nyebut nilai-nilai kebaikan itu dalam syair-syair mereka dalam rangka mengabadikannya dan untuk memotivasi para pembacanya agar tetap memegang teguh nilai-nilai tersebut. Salah seorang pujangga Arab menggubah syairnya:

Kapan saja aku menyeru kaumku

Para ksatria perang bangsawan pasti menjawab seruanku Engkau lihat orang yang tersuaka merasa aman di tengah- tengahmereka

Hidup di bawah perjanjian yang sangat kokoh

Apabila kami telah memberinya perjanjian perlindungan Maka, kami memegangnya dengan teguh

Melalui syairnya pula, pujangga Arab yang lain menyuarakan:

Pengungsi datang kepada kami mencari perlindungan dari rasa takut

Berharap dan kami menawarkan kepadanya suaka Dia hidup di bawah suaka yang bermartabat

Semua itu sepanjang musim panas hingga berakhirnya musim dingin

Kami menjamin harta mereka, maka esok akan selamat Kami harus menjamin kekurangan dan kelebihannya

Dan saya tidak melihat orang ditawan sebagai yang dikorbankan Dan saya tidak melihat tetangga rumah yang diusir

Tetangga rumah dan lelaki yang menyerunya

Perjanjian keduanya sama dihadapan kehidupan

Pemberian perlindungan/suaka dan penerimaan atas permintaan perlindungan/suaka memperoleh porsi perhatian tersendiri dalam syair-syair para pencari perlindungan/suaka (al-mustajirin) (Ardhiwisastra, 2013). Di sisi lain, siapa saja yang tidak mengabulkan permintaan mencari suaka akan merasakan betapa pahitnya rasa bahasa yang diekspresikan para pujangga melalui syair-syair mereka, disamping mendapatkan tatapan yang mencerminkan celaan dan ejekan (Parthiana, 2014).

Telah nyata bahwa pemberian suaka itu bertujuan mewujudkan rasa aman dan kenyamanan secara penuh kepada pengungsi.Hal demikian nampak jelas dengan adanya Sumpah 'Aqabah kedua tentang kesetiaan (bay'ah) yang mendahului peristiwa hijrah Nabi Muhammad SAW ke Madinah. Ketika warga Yatsrib menerima migrasi (hijrah)-nya Rasulullah ke daerah mereka maka Nabi Muhammad SAW berkata: "Sayaakan memberikan sumpah untuk melindungi, asalkan kamu semua juga melindungi dan membela saya sebagaimana kamu sekalian membela isteri 
dan anak kalian.”

Bangsa Arab (pra-Islam) dan bangsa Muslim dalam hal ini memiliki kepioniran dalam beberapa hal. Abd al-Malik ibn Marwân berkata kepada Ju'ail ibn "Alqamah: "Seberapa jauh perlindungan yang Engkau tawarkan untuk orang lain?". Ia menjawab: "Siapapun di antara kami akan membela orang yang telah memberi kepadanya perlindungan dari ancaman kaum lain, sebagaimana ia membela dirinya sendiri."Abd al-Malik berkata: "Seperti halnya kamu pula ketika orang mensifati kaumnya."Telah jelas bahwa ada kebiasaan bahasa Arab, sebagai bahasa al-Qur'an, untuk menggunakan sejumlah kata untuk mengungkapkan satu konsep/gagasan dan satu sistem mengenai hak untuk suaka. Terkadang digunakan pula kata al-îwâ' (إليواء yang berarti perlindungan) sebagaimana terdapat dalam Q.S. al-Anfâ ayat 26, 72, 74, dan Q.S. al- Duha:6, yakni: yang artinya:

dan ingatlah (hai orang-orang yang hijrah) ketika kamu masih berjumlah sedikit, lagi tertindas di muka bumi (Mekkah), kamu takut orang-orang (Mekkah) akan menculik kamu. Maka, Allah memberi kamu tempat menetap (Madinah) dan dijadikan-Nya kamu kuat dengan pertolongan-Nya dan diberi-Nya kamu rezeki dari yang baikbaik agar kamu bersyukur. (Q.S .al-Anfâl:26).

Selanjutnya dalam Q.S. al-Anfâl:72 yang artinya: Sesungguhnya orang-orang beriman, hijrah serta berjihad dengan harta dan jiwanya pada jalan Allah danorang-orang yang memberikan tempat kediaman dan pertolongan (kepada orang-orang yang hijrah ), mereka itu satu sama lain saling melindungi, dan (terhadap) orang-orang beriman, tetapi belum hijrah, maka tidak ada kewajiban sedikitpun atasmu melindungi mereka, sebelum mereka ber-hijrah. (Akan tetapi) Jika mereka meminta pertolongan kepadamu dalam (urusan pembelaan) agama, maka kamu wajib memberikan pertolongan kecuali terhadap kaum yang telah ada perjanjian antara kamu dengan mereka. Dan Allah Maha Melihat apa yang kamu kerjakan. (Q.S. al-Anfâl:72)

Kemudian dijelaskan juga dalam Q.S. al- Anfâl:74 yang artinya: dan orang-orang beriman, hijrah serta berjihad pada jalan Allah, dan orang-orang yang memberi tempat kediaman dan memberi pertolongan (kepada orang-orang yang hijrah), mereka itulah orangorang yang benar-benar beriman. Mereka memperoleh ampunan dan rezki (nikmat) yang mulia. (Q.S. al- Anfâl:74).

Terkadang digunakan pula kata al-hijrah ()جرة) untuk menunjuk makna hak untuk mengungsi, seperti dalam Q.S. al- Hasyr:9 yang menyatakan bahwa:

Dan orang-orang yang telah menempati kota Madinah dan telah beriman (Anshor) sebelum (kedatangan) mereka (Muhajirin), mereka (Anshor) 'mencintai' orang yang berhijrah kepada mereka (Muhajirin). Dan mereka (Anshor) tiada menaruh keinginan dalam hati mereka terhadap apa-apa yang diberikan kepada mereka (Muhajirin); dan mereka mengutamakan (orang- orang muhajirin), atas diri mereka sendiri, sekalipun mereka dalam kesusahan. Dan siapa yang dipelihara dari kekikiran dirinya, mereka itulah orang orang yang beruntung. (Q.S. al- Hasyr:9)

Demikian pula halnya penggunaan kata al-malja' untuk menunjuk konsep/ gagasan ini. Al-Qur'an menggunakan kata al- malja'lebih dari satu 
tempat, di antaranya ialah:

Dan mereka (orang-orang munafik) bersumpah dengan (nama) Allah, bahwa sesungguhnya mereka termasuk golongankamu, padahal mereka bukanlah dari golonganmu, tetapimereka adalah orang-orang yang sangat takut (kepadamu). (Q.S. al-Taubah:56)

Jikalau mereka memperoleh tempat perlindunganmu atau gua- gua atau lobang-lobang (dalam tanah) niscaya mereka pergi kepadanya dengan secepat-cepatnya. (Q.s. al-Taubah:57)

Dan terhadap tiga orang yang ditangguhkan (penerimaan taubat) mereka, hingga apabila bumi telah menjadi sempit bagi mereka, padahal bumi itu luas dan jiwa merekapun telah sempit pula( terasa) oleh mereka, serta mereka telah mengetahui bahwa tidak ada tempat lari dari (siksa) Allah, melainkan kepada-Nya saja. Kemudian Allah menerima taubat mereka agar mereka tetap dalam taubatnya. Sesungguhnya Allah-lah yang Maha Penerima taubat lagi Maha Penyayang. (Q.S. al-Taubah:118).

Patuhilah seruan Tuhanmu sebelum datang dari Allah suatu hari yang tidak dapat ditolak kedatangannya. Kamu tidak memperoleh tempat berlindung pada hari itu dan tidak (pula) dapat mengingkari (dosadosamu). (Q.S.al-Syûra: 47). Kata al-malja' dalam bahasa Arab, semakna dengan kata adzm yang artinya "menaungi" dan "melindungi", sedang kata dzamm mengandung arti "mencela" âba. Di dalam bahasa Arab terdapat ungkapan his $\underline{s} h n i$ (pemeliharaanku), maljâi (perlindunganku), malâdzi, (perlindunganku), maw'ilî (perlindunganku), ma'qilî (pemeliharaanku), ma'âdẑ (perlindunganku), wizrî (bebanku), kahfi (perlindunganku), maqsadî (tujuanku), mu'tamadí (sandaranku), mu'tadadí (sandaranku), hîirdâ (pemeliharaanku), mu'tasamî (pemeliharaanku), manjaya (penyelamatanku), mahîsî (perlindunganku), ma'ah (perlindunganku), kanafi (pemeliharaanku), istajârahu (meminta perlindungan), istassrakha-hu (meminta pertolongan), istinjadahu (meminta pertolongan), istinsyârahu (meminta nasehat), istijâsyahu (meminta perlindungan), lahifa ilaihi (mengadu kepadanya), jaza'a ilaihi (berkeluh kesah kepadanya), istizara bihi (meminta pertolongan kepadanya), isytawhasya ilaihi (menjadi senang kepadanya).Dari kata-kata tersebut pula terbentuk kata al-istiadzah yang bermakna sama secara etimologis, yakni melindungi, memelihara, menaungi. Secara spesifik kata إلستعاذة muncul dalam Q.S. al- Nahl:98 yang menyatakan bahwa: yang artinya: Apabila kamu membaca al-Qur'an hendaklah kamu meminta perlindungan kepada Allah dari syaitan yang terkutuk. (Q.S. al- Nahl:98).

\section{Persyaratan Memperoleh Suaka Menurut Hukum Islam}

Suaka sesuai dengan ketentuan Syariat Islam maka harus dipenuhi persyaratan berikut ini. Pertama; Pencari suaka berada di negara Islam atau di wilayah yang tunduk kepada negara Islam. Hal ini masuk akal, sebab, untuk dapat diberikan suaka oleh suatu negara Islam, pencari suaka harus berada di wilayah negaraIslamitu.Sebutan"negaraIslam"mencakup wilayahwilayah di mana Syariat Islam diterapkan, dan orang-orang yang menghuninya, baik Muslim, non-Muslim (dzimmiy) maupun orang lainnya, berada di bawah perlindungan Islam dan dilindungi atas dasar ajaran Islam. Dalam kaitan ini, Abu Hanîfah mengemukakan 3 (tiga) syarat mengenai apa yang disebut sebagai negara Islam (Dâr al-Islâm). Pertama, aturan-aturan 
yang ditegakkan bersumber dari Syariat Islam.Kedua, negara itu bertetangga dengan negara-negara Islam lainnya.Ketiga, penduduknya, baik Muslim maupun non-Muslim, dilindungi atas dasar ajaran Islam (Santoso, 2012).Kalangan ulama mazhab Mâliki berpendapat bahwa yang disebut sebagai negara Islam (Dâr al-Islâm) ialah negara yang memberlakukan aturan Muslim (Syariat Islam) dalam sistem hukumnya.

Kalangan ulama mazhab Syâfi'i berpandangan bahwa yang disebut sebagai negara Islam (Dâr al-Islâm) ialah negara yang penduduknya diberi ruang untuk menegakkan aturan-aturan Islam (Syariat Islam). Sedangkan fikih mazhab Hanbali mengaskan bahwa setiap negara di mana sistem hukumnya didominasi oleh aturan Islam (Syariat Islam) merupakan negara Islam (Dâr al-Islâm); dan sebaliknya, setiap negara di mana sistem hukumnya didominasi hukum non-Islam merupakan negara non-Islam( $D a ̂ r$ al-Kufr); dan tidak ada negara selain kedua macam negara tersebut. Begitu pula halnya, suaka/perlindungan dapat diberikan, seperti akan kita bahas lebih lanjut, di wilayah-wilayah yang tunduk kepada negara-negara Islam (seperti tempat- tempat misi diplomatik atau kapal perang). Para ulama fikih juga mengakui suaka/perlindungan yang diberikan negara-negara lain, dan ini sejalan dengan penerapan asas yurisdiksi-teritorial dan asas yurisdiksi non-perluasan teritorial negara Islam ke wilayah yang bukan bagian dari negara Islam. Kedua; Terdapat motif untuk memperoleh suaka dan dalam pandangan Islam, semua motif itu adalah setara. Disyaratkan adanya motif memperoleh suaka. Namun, tidak disyaratkan si pencari suaka itu hanya lari ke negara Islam lantaran takut terhadap penganiayaan yang akan menimpanya. Lebih dari itu, suaka dapat diberikan kepada setiap orang yang ingin tinggal di negara Islam, baik dengan alasan ia telah memeluk agama Islam ataupun alasan ia ingin tetap menjadi warga negara dengan status ahl al-dzimmah (non-Muslim dibawah perlindungan negara Islam) (Syahrin, Artono, \& Santiago, 2018).

Dengan demikian, tidak seperti ketentuan Konvensi 1951 dan Protokol 1967 yang mengatur status pengungsi, yang membatasi pengertian "pengungsi" pada orang yang lari dari negaranya lantaran takut akan penindasan/penyiksaan yang menimpanya, Islam menerapkan pengertian "pengungsi" yang lebihluas.Ketiga; Ketidakinginan atau ketidakmungkinan pencari suaka memperoleh perlindungan dari negaraasalnya.Kedatangan si pencari suaka ke negara Islam dan keinginannya tinggal di negara itu menunjukkan ketidakinginan atau ketidakmungkinan tersebut.Telah dikemukakan bahwa makna kata "istijârah" menunjukkan hal tersebut.Demikian pula, makna kata "ijârah" yang terdapat di dalamalQur'an.Keempat; Ketiadaan pertentangan antara pemberian suaka dengan prinsip-prinsip Syariat Islam. Sudah sewajarnya bahwa pemberian suaka, baik dari segi substansinya, hasilnya maupun dampaknya, tidak boleh melanggar atau bertentangan dengan prinsip- prinsip dan ajaran Q.S. alHasyr:9 menetapkan 5 (lima) prinsip utama terkait suaka dan tata cara penanganan terhadap pengungsi. Allah SWT berkalam: yang artinya: dan orang-orang yang telah menempati kota Madinah dan telah beriman (ansâr) sebelum (kedatangan) mereka (muhâjirîn), mereka (anşâr) mencintai orang yang hijrah kepada mereka (muhâjirîn). Dan mereka (anșâr) tiada menaruh keinginan dalam hati mereka terhadap apa-apa yang diberikan kepada mereka (muhâjirîn); dan mereka mengutamakan (orang-orang muhajirin), 
atas diri mereka sendiri, Sekalipun mereka dalam kesusahan.Dan siapa yang dipelihara dari kekikiran dirinya, mereka Itulah orang orang yang beruntung. (Q.S. al- $\underline{\text { Hasyr:9). }}$.

Dari ayat ini terlihat jelas prinsip-prinsip di bawah ini:

1. Kaum Muslim sepantasnya bersikap senang dan gembira menyambut kedatangan pengungsi (atau imigran dari suatu wilayah ke wilayah lain) dan bergaul secara baik dengan mereka. Ini terlihat jelas dari kalam Allah: "...mereka (anșâr) mencintai orang yang hijrah kepada mereka (muhâjirîn)...". Oleh karena itu, para pencari suaka tidak boleh diusir ke luar batas teritori negara Islam atau ditolakkedatangannya.

2. Kaum Muslim sepantasnya memperlakukan mereka dengan baik, dan memprioritaskan kepentingan/kebutuhan hidup mereka. Ini terlihat jelas dari kalam Allah: “...dan mereka mengutamakan (orang- orang muhajirin), atas diri mereka sendiri...”. Yang dimaksud dengan al-îtsâr ialah lebih mengutamakan orang lain ketimbang dirinya sendiri perihal kebutuhan/kepentingan duniawi lantaran lebih menginginkan keuntungan ukhrawi. Sikap ini lahir dari sikap percaya diri yang kokoh, kecintaan kepada Allah yang mendalam, dan kesabaranterhadap kesulitan (Tickner, 2014). Seperti demikian halnya, karena sikap lebih mengutamakan orang lain dalam urusan hidup berada di atas sikap lebih mengutamakan orang lain dalam urusan harta sekalipun kembalinya kepada urusan hidup juga.

3. Penerimaan simpatik terhadap pengungsi, baik yang kaya maupun yang miskin. Ini terlihat jelas dari kalam Allah: "Dan mereka (ansâr) tiada menaruh keinginan dalam hati mereka terhadap apa-apa yang diberikan kepada mereka (muhâjirîn)...". Dengan demikian, apakah pengungsi itu orang kaya atau miskin tidak punya pengaruh apapun, karena masalah ini hanya berkaitan dengan upaya perlindungan dan jaminan keamanan serta kesejahteraan terhadap diri pengungsi di daerah/negara tujuan.

4. Ketidakbolehan menolak imigran sekalipun penduduk daerah/negara tujuan migrasi para imigran itu tengah mengalami krisis, kemiskinan dan kebutuhan hidup yang meningkat. Ini terlihat jelas dari kalam Allah: "Sekalipun mereka dalam kesusahan...",yakni kemiskinan kebutuhan hidup yang mendesak atau sedikitnya harta kekayaan.

5. Ayat ini juga membuktikan adanya suaka teritorial, hal ini tercermin dalam ayat: : "Dan orang-orang yang telah menempati kota Madinah dan telah beriman (ansâr) sebelum (kedatangan) mereka (muhâjïrîn)...”. Maksudnya, mereka yang tinggal di negeri itu dan menjadikannya sebagai tanah kediaman mereka. ${ }^{40}$ Ini menunjukkan bahwa penduduk daerah/wilayah tujuan migrasi wajib menerima kedatangan imigran ke daerah/negaramereka.

Pengungsi adalah setiap orang yang mengalami rasa takut akan kemungkinan adanya penindasan/penyiksaan terhadap dirinya lantaran rasnya, agamanya, kebangsaannya atau keanggotaannya (afiliasinya) kepada kelompok sosial tertentu atau pandangan politiknya (UNHCR, 2016), di luar negara yang menaungi kebangsaannya, dan ia tidak mampu atau tidak ingin memperoleh perlindungan dari negara itu lantaran rasa takut tersebut, atau setiap orang yang tidak memiliki kebangsaan dan berada di luar negara tempat ia sebelumnya tinggal sehingga ia tidak mampu atau tidak ingin, lantaran rasa takut itu, pulang kembali ke negaranya (Syahrin, 2018i, 2018j, 
2018k, 2018l).

Terlihat jelas dari pengertian yang tercantum pada Pasal 1 Konvensi 1951 dan Protokol 1967 bahwa sebelum memeperoleh status "pengungsi", seseorang diharuskan memenuhi persyaratan berikutini:pertama; orang tersebut berada di luar negara yang menjadi identitas kebangsaannya atau di luar negara yang biasa didiaminya apabila ia berstatus tidak punya kewarganegaraan. Kedua; adanya kekhawatiran atas timbulnya faktor yang membenarkannya untuk mengalami penganiayaan lantaran rasnya, agamanya, kebangsaannya, atau afiliasinya kepada kelompok sosial tertentu, atau lantaran pandangan politiknya.Ketiga; pengungsi itu tidak mampu atau tidak ingin berada dalam perlindungan negara asalnya atau negara yang biasa dialaminya atau apabila ia berstatus tidak punya kewarganegaraan dari negara asalnya atu negara yang biasa didiaminya (UNHCR, 2015).

Pengertian "pengungsi" yang tercantum dalam Konvensi 1951 tersebut, kemudian diperluas sebagaiberikut (Sanyal, 2014).Pertama; konvensi Organisasi Persatuan Afrika tentang Aspek-Aspek Khusus Problem Pengungsi di Afrika (1969) memberi tambahan atas definisi "pengungsi" yang tercantum dalam Konvensi 1951 sebagai berikut:Bahwa kata "pengungsi" juga berlaku bagi setiap orang yang terpaksa harus meninggalkan negaranya dan mencari suaka di luar negaranya atau tempat tinggal asalnya lantaran adanya agresi asing, pendudukan asing, penguasaan asing, atau peristiwa yang mengganggu kepentingan umum di suatu bagian atau seluruh wilayah negara orang tersebut. Dengan demikian, sesuai dengan Konvensi ini, seseorang dapat disebut sebagai pengungsi apabila mengalami keadaan seperti di atas, meskipun ia tidakmengalami ketakutan terhadap penyiksaan/penindasan (Syahrin, 2018m, 2018n, 2018o, 2018p).

Konvensi ini bersandarkan pada prinsip bahwa perlindungan internasional harus diberikan kepada pengungsi ketika tidak ada perlindungan negara asal mereka lantaran negara mereka itu tidak mampu atau tidak mau memberikan jaminan perlindungan kepada warga negaranya. Hal ini biasanya terjadi di tengah situasi peperangan atau pendudukanmiliter. Kedua; Deklarasi Cartagena tentang Pengungsi (1984) memberi tambahan atas definisi "pengungsi" yang tercantum dalam Konvensi 1951, yakni bahwa kata atau konsep "pengungsi" juga berlaku bagi setiap orang yang lari dari negaranya lantaran kehidupannya, keselamatannya atau kebebasannya terancam oleh kekerasan yang meluas, agresi asing, konflik di dalam negeri (Wu, 2017), pelanggaran hak asasi manusia secara luas, atau situasi apapun yang membahayakan ketertiban umum (Syahrin, 2018q; Syahrin, Arifin, \& Nursanto, 2018). Meskipun Deklarasi ini tidak mengikat karena hanya deklarasi semata, bukan perjanjian internasional yang mengikat, sehingga tidak berlaku terhadapnya "pacta sunt servanda" (perjanjian mengikat para pihak yang membuatnya) atau prinsip "ex consensus advenit vinculum" (kesepakatan bersifat mengikat); akan tetapi, prinsip ini diimplementasikan dalam praktik hukum dan legislasi nasional di sebagian negara-negara AmerikaTengah (Syahrin, 2018d; Syahrin \& Irsan, 2018; Syahrin \& Pasaribu, 2018; Syahrin \& Pranata, 2018).

Lebih lagi, Pasal 14 Deklarasi Universal tentang Hak Asasi Manusia menyatakan bahwa:

(1) setiap orang berhak mencari dan menikmati suaka untuk memperoleh 
perlindungan dari negara pemberi suaka dan untuk menghindaripenyiksaan/penindasan.

(2) hak ini tidak dapat diperoleh apabila keadaan itu lahir atas dasar tindak pidana/kejahatan non-politik atau lantaran perbuatan yang melanggar tujuan-tujuan dan prinsip-prinsip PBB.

Lebih jauh lagi, hak suaka diartikan diperolehnya perlindungan yang diberikan oleh suatu negara, di wilayah negara tersebut atau di wilayah lain yang tunduk kepada pemerintah negara tersebut, kepada seseorang yang meminta suaka/perlindungan. (UNHCR, 2011).

Hak suaka mengandung 3 (tiga) komponen, yaitu:pertama; masuknya seseorang kedalam suatu teritori tertentu, dengan asumsi ia mencari suaka (dalam bahasa hukum, ini disebut îjâb), yang kemudian dijawab dengan persetujuan negara tujuan (dalam bahasa hukum, disebut qabût).Kedua; pemberian izin kepada pencari suaka untuk menetap di wilayah negaratujuan.Inimelahirkan2(dua)implikasipenting,yaitu (1) pencari suaka tersebut tidak boleh dipulangkan ke negaranya; dan (2) pencari suaka tersebut tidak boleh diekstradisi ke suatu negara atau pihak lain yang memintanya, apabila hal ini akan berakibat hukuman atau penganiayaan bagi pencari suakatersebut.Ketiga; pencari suaka itu tidak boleh dihukum lantaran memasuki wilayah negara tersebut secara ilegal, Hal ini dibenarkan menurut konsep alasan darurat yang mendorong pencari suaka itu lari dari negaranya ke negara lain karena menghindari penganiayaan yang akan dialami diri yangbersangkutan (UNHCR, 2012).

\section{Kesimpulan}

Perlindungan hukum pencari suaka dan pengungsi dalam hukum Islam telah lama terjadi sehingga menjadi tradisi masyarakat Arab yang telah mengakar kuat, yang dilarang keras untuk dilanggar, pemberian perlindungan hukum kepada orang yang sangat membutuhkan merupakan perilaku mulia bangsa Arab dan umat Muslim dalam Al-quran sebagaimana dijelaskan dalam Q.S. al-Hasyr:9. Sedangkan perlindungan hukum terhadap pencari suaka dalam hukum internasional sebagaimana diatur dalam Pasal 14 Deklarasi Universal tentang Hak Asasi Manusia menyatakan bahwa: setiap orang berhak mencari dan menikmati suaka untuk memperoleh perlindungan dari negara pemberi suaka dan untuk menghindari penyiksaan/penindasan, dan hak ini tidak dapat diperoleh apabila keadaan itu lahir atas dasar tindak pidana/kejahatan non-politik atau lantaran perbuatan yang melanggar tujuan-tujuan dan prinsip-prinsip PBB.

\section{DAFTAR PUSTAKA}

Ardhiwisastra, Yudha Bhakti. (2013). Imunitas Kedaulatan Negara di Forum Pengadilan Asing. Bandung: Alumni.

El-Wafa, Ahmed Abou.(2009). Hak-Hak Pencarian Suaka dalam Syariat Islam dan Hukum Internasional. Riyadh: UNHCR Indonesia dan UIN Syarif Hidayatullah.

Hadi, Abdul. "Posisi Wanita Dalam Sistem Politik Islam Perspektif Fenomelogi”. An Nisa'a 12, no. 1 (October 12, 2017): 9-20. Accessed Jan 28, 2019. http://jurnal.radenfatah.ac.id/index.php/annisa/article/view/ $\underline{1500}$ 
Hamid, Sulaiman. (2012). Lembaga Suaka dalam Hukum Internasional. Jakarta: Rajawali Pers.

Hashimoto, N. (2018). Refugee resettlement as an alternative to asylum. Refugee Survey Quarterly, 37(2). https://doi.org/10.1093/rsq/hdy004

Parthiana, Wayan. (2014). Beberapa Masalah dalam Hukum Internasional dan Hukum Nasional Indonesia. Jakarta.

Santoso, M. Iman. (2012). Perspektif Imigrasi dalam Migrasi Manusia. Bandung: Pustaka Reka Cipta.

Sanyal, R. (2014). Urbanizing refuge: Interrogating spaces of displacement. International Journal of Urban and Regional Research. https://doi.org/10.1111/1468-2427.12020

Syahrin, M. A. (2014a). Menakar Eksistensi Area Imigrasi. Bhumi Pura, 10(1), 39-41. Retrieved from https://drive.google.com/file/d/ 0B7I_Y1ukAV9YWVFPVFVtYWVQNVE/view

Syahrin, M. A. (2014b). Penegasan Asas Kewarganegaraan dalam UU No. 12 Tahun 2006. Bhumi Pura, 8(1), 33-35. Retrieved from https://drive.google.com/file/d/0B7I_Y1ukAV9YVDNhT0ZRcjdicU0/view

Syahrin, M. A. (2014c). Penyadapan oleh Australia, Saatnya Imigrasi Bersikap. Bhumi Pura, 1(1), 30-35. Retrieved from https://drive.google.com/file/d/0B7I_Y1ukAV9YMlRMYVBwZm80b0E/vie $\mathrm{w}$

Syahrin, M. A. (2014d). Perkembangan Konsep Nasionalisme di Dunia. Bhumi Pura, 11(1), 23-24. Retrieved from https://drive.google.com/file/d/0B7I_Y1ukAV9YV0hxY1hLVC1HRlU/view

Syahrin, M. A. (2014e). Refleksi Hubungan Negara, Warga Negara, dan Keimigrasian. Bhumi Pura, 8(1), 36-38. Retrieved from https://drive.google.com/file/d/0B7I_Y1ukAV9YU3oteFZ5ZEVpZ2c/view

Syahrin, M. A. (2015a). Beri Efek Jera Pada Pelaku Kejahatan Keimigrasian. Bhumi Pura, 8(1), 16-21. Retrieved from https://drive.google.com/file/d/0B7I_Y1ukAV9YLUtuMnZMVzlsR2M/view

Syahrin, M. A. (2015b). Hak Asasi Bermigrasi. Bhumi Pura, 11(1), 45-48. Retrieved

from https://drive.google.com/file/d/0B7I_Y1ukAV9YY1hiSzNkNHozQTg/view

Syahrin, M. A. (2015c). Imigran Ilegal, Migrasi atau Ekspansi? Checkpoint, 3(1), 29-31. Retrieved from https://drive.google.com/file/d/0B7I_Y1ukAV9YcWFhdllUODlxVlU/view

Syahrin, M. A. (2015d). Memaksimalkan Peran Imigrasi di Perbatasan. Bhumi Pura, 2(1), 38-40. Retrieved from https://drive.google.com/file/d/0B7I_Y1ukAV9YdzEwRVh1VEJzTjQ/view

Syahrin, M. A. (2016a). Antara Batas Imajiner dan Kedaulatan Negara. In Imigrasi di Batas Imajiner (TPI Soekarno Hatta) (1st ed., Vol. 1, pp. 1631). Jakarta: Kantor Imigrasi Kelas I Khusus Soekarno Hatta. Retrieved from https://drive.google.com/file/d/0B7I_Y1ukAV9Yd2JrLW4wWGlERmM/vie $\mathrm{w}$

Syahrin, M. A. (2016b). Eksodus Warga Negara Tiongkok: Antara Kebijakan dan Penyelundupan. Bhumi Pura, 6(1), 38-40. Retrieved from https://drive.google.com/file/d/0B7I_Y1ukAV9YRnl4d3owdjAydVE/view

Syahrin, M. A. (2016c). Reorientasi Fungsi Imigrasi Indonesia. In Imigrasi di Batas Imajiner (TPI Soekarno Hatta) (1st ed., Vol. 1, pp. 89-102). 
Jakarta: Kantor Imigrasi Kelas I Khusus Soekarno Hatta. Retrieved from

https://drive.google.com/file/d/0B7I_Y1ukAV9YRGo3YU0zMW5vQW8/vie $\mathrm{w}$

Syahrin, M. A. (2017a). Actio Pauliana: Konsep Hukum dan Problematikanya. Lex Librum, 4(1), 605-616. Retrieved from http://lexlibrum.id/index.php/lexlibrum/article/view/97

Syahrin, M. A. (2017b). E-Commerce: Pilihan Hukum dan Pilihan Forum (1st ed.). Tangerang: Mahara Publishing. Retrieved from https://drive.google.com/file/d/0B7I_Y1ukAV9YcWlLVFd3RGJEa1k/view

Syahrin, M. A. (2017c). Imigran Ilegal dan HAM Universal. Bhumi Pura, 5(1), 29-34. Retrieved from https://drive.google.com/file/d/1y319VmqEzhGr4HEpMh2nYMIXQh1Vys tk/view

Syahrin, M. A. (2017d). Konsep Teoretis Penyelesaian Sengketa Hukum ECommerce (1st ed.). Tangerang: Mahara Publishing. Retrieved from https://drive.google.com/file/d/0B7I_Y1ukAV9Yci0yV2ZQd0Jjc28/view

Syahrin, M. A. (2017e). Nomenklatur Pengawasan dan Penindakan Keimigrasian di Daerah, Perlukah Dipisah? Bhumi Pura, 5(1), 40-43. Retrieved from https://drive.google.com/file/d/11vX3uZDT6eqb3qQy39u0thoKZgyNhX17/ view

Syahrin, M. A. (2017f). Penerapan Hukum Deteni Tanpa Kewarganegaraan (Stateless) yang Ditahan Lebih Dari 10 (Sepuluh) Tahun di Rumah Detensi Imigrasi Jakarta. Fiat Justicia, 3(2), 455-481. Retrieved from http://journal.ukb.ac.id/journal/detail/197/penerapan-hukum-detenitanpa-kewarganegaraan-stateless-yang-ditahan-lebih-dari-10-sepuluhtahun-di-rumah-detensi-imigrasi-jakarta:-studi-kasus-danko-nizar-zlavic

Syahrin, M. A. (2017g). Posisi dan Perkembangan Hukum Pengungsi Internasional. Bhumi Pura, 5(1), 45-48. Retrieved from https://drive.google.com/file/d/1fIchcDE8wZBarEBTb9ZUFGVMRDXogv $\mathrm{NB} /$ view

Syahrin, M. A. (2017h). Refleksi Teoretik E-Contract: Hukum yang Berlaku Dalam Sengketa Transaksi Bisnis Internasional yang Menggunakan ECommerce. Lex Librum, 3(2), 475-494. Retrieved from http://lexlibrum.id/index.php/lexlibrum/article/view/55

Syahrin, M. A. (2017i). The Implementation of Non-Refoulement Principle to the Asylum Seekers and Refugees in Indonesia. Sriwijaya Law Review, 1(2), 168-178. Retrieved from http://journal.fh.unsri.ac.id/index.php/sriwijayalawreview/issue/view/7

Syahrin, M. A. (2018a). Aspek Hukum Laboratorium Forensik Keimigrasian: Studi Kasus Pemeriksaan Paspor Palsu Kebangsaan Inggris atas nama Abbas Tauqeer. Akta Yudisia, 3(1), 104-135. Retrieved from https://drive.google.com/file/d/15QDWcZTUyMa0Gfh9IwXuCHszXDQ4vg $\mathrm{rX} / \mathrm{view}$

Syahrin, M. A. (2018b). E-Commerce Dispute Settlement: The Determination of Authorized Forums. In International Conference on Continuing Professional Development on Law Expert and Mediation Process (Vol. 1, pp. 11-20).

Syahrin, M. A. (2018c). Indonesia Darurat Imigran Ilegal. Checkpoint, 5(1), 
18-19. Retrieved from https://drive.google.com/file/d/16c9lFosdUnTz6jhpPPHYlK_LV-MZ6xF/view

Syahrin, M. A. (2018d). Jus Cogens dalam Protokol Penyelundupan Migran Tahun 2000. Bhumi Pura, 2(1), 13-16. Retrieved from https://drive.google.com/file/d/1wi2R2OS18aRWEOh1VfDnke_Hv4gq4X4 $\mathrm{K} / \mathrm{view}$

Syahrin, M. A. (2018e). Landasan Teoretis Penyelesaian Sengketa Hukum Perbankan Syariah (1st ed.). Depok: Politeknik Imigrasi. Retrieved from https://drive.google.com/file/d/1Ifh-TtEO2iM8MrFSo8aC$6 \mathrm{fFoU} 1 \mathrm{iVYrw} / \mathrm{view}$

Syahrin, M. A. (2018f). Menakar Kedaulatan Negara dalam Perspektif Keimigrasian. Jurnal Penelitian Hukum De Jure, 18(1), 43-57. Retrieved from http://ejournal.balitbangham.go.id/index.php/dejure/article/view/331/pdf

Syahrin, M. A. (2018g). Mengukur Kekuatan Hukum Surat Edaran. Bhumi Pura, 6(1), 48-50. Retrieved from https://drive.google.com/file/d/1eg7RLilrpqBVt1Xm9qFnAdVV1Nh90LL2/ view

Syahrin, M. A. (2018h). Pembatasan Prinsip Non-Refoulement. Bhumi Pura, 1(1), 12-16. Retrieved from https://drive.google.com/file/d/1xvl2S6lBNiczXh8VzjQ9y_kBOpzdKbt/view

Syahrin, M. A. (2018i). Penentuan Forum yang Berwenang dan Model Penyelesaian Sengketa Transaksi Bisnis Internasional Menggunakan ECommerce: Studi Kepastian Hukum dalam Pembangunan Ekonomi Nasional. Rechtsvinding, 7(2), 207-228. Retrieved from https://rechtsvinding.bphn.go.id/ejournal/index.php/jrv/article/view/240

Syahrin, M. A. (2018j). Penerapan Prinsip Keadilan Restoratif dalam Sistem Peradilan Pidana Terpadu. Majalah Hukum Nasional, 1(1), 97-114. Retrieved from https://mhn.bphn.go.id/index.php/mhn/article/view/10/39

Syahrin, M. A. (2018k). Penerapan Wewenang Penyidik Pegawai Negeri Sipil dalam Melakukan Penyidikan Tindak Pidana Keimigrasian. Seminar Hukum Nasional, 4(1), 25-49. Retrieved from https://journal.unnes.ac.id/sju/index.php/snh/article/view/25555

Syahrin, M. A. (20181). Pro dan Kontra Penerbitan Perpres No. 20 Tahun 2018 tentang Penggunaan Tenaga Kerja Asing. Bhumi Pura, 3(1), 22-25. Retrieved from https://drive.google.com/file/d/1Yx9HT0mMWHHrGtKPhGujp_w9rOqYL Jr1/view

Syahrin, M. A. (2018m). Refleksi Hukum Implementasi Kebijakan Bebas Visa Kunjungan dalam Perspektif Keimigrasian. Fiat Justicia, 4(2), 155-169. Retrieved from http://journal.ukb.ac.id/journal/detail/300/refleksihukum-implementasi-kebijakan-bebas-visa-kunjungan-dalamperspektif-keimigrasian

Syahrin, M. A. (2018n). Sengketa Hukum Perbankan Syariah: Dualisme Kompetensi Absolut Peradilan (1st ed.). Depok: Politeknik Imigrasi. Retrieved from https://drive.google.com/file/d/1lkGUDGUsp48UgGGqPVhurYCd1u7gag $\mathrm{Qd} / \mathrm{view}$

Syahrin, M. A. (20180). The Immigration Crime and Policy: Implementation 
of PPNS Authorities on Investigation. JILS, 3, 175. https://doi.org/https://doi.org/10.15294/jils.v3i02.27512

Syahrin, M. A. (2018p). The Legal Concepts of Abuse of Dominant Position on Monopolistic Practices and Unfair Business Competition. In International Conference on Applied Business and Economics (Vol. 14, pp. 357-363).

Syahrin, M. A. (2018q). The Rohingya Refugee Crisis: Legal Protection on International Law and Islamic Law. In International Conference on Indonesian Legal Studies (Vol. 192, pp. 94-99).

Syahrin, M. A., Arifin, R., \& Nursanto, G. A. (2018). Regulasi Pemeriksaan Keimigrasian di Indonesia (1st ed.). Depok: Politeknik Imigrasi. Retrieved from https://drive.google.com/file/d/1l_p8mZhgacU01iblvI11xkZ204IrQQ7/view

Syahrin, M. A., Artono, H. B., \& Santiago, F. (2018). Legal Impacts of The Existence of Refugees and Asylum Seekers in Indonesia. International Journal of Civil Engineering and Technology, 9(5), 1051-1058. Retrieved from

http://www.iaeme.com/MasterAdmin/UploadFolder/IJCIET_09_05_117/I JCIET_09_05_117.pdf

Syahrin, M. A., \& Irsan. (2018). Law Enforcement of Foreign Workers Abusing Immigration Residence Permit: Case Studies on Energy and Mining Companies. In International Conference on Energy and Mining Law (Vol. 59, pp. 184-189).

Syahrin, M. A., \& Pasaribu, P. Y. (2018). Dialektika Hukum Determinasi Migrasi Pengungsi di Indonesia. Jurnal Ilmiah Kajian Keimigrasian, 1(1), 150-164. Retrieved from https://drive.google.com/file/d/1BfjOKtZq6RJIxOrJW5oucmZuRmGhIJV $\mathrm{O} /$ view

Syahrin, M. A., \& Pranata, S. (2018). Studi Kritis Kepentingan Indonesia dalam Proses Ratifikasi Konvensi Tahun 1951 dan Protokol Tahun 1967. Jurnal Ilmiah Kajian Keimigrasian, 1(1), 49-62. Retrieved from https://drive.google.com/file/d/1zxq2aqjTbQpcl8yPuvh5GhnXwSJoAJVE/ view

Tickner, J. Ann. (2014). Revisioning Security: International Relations Theory Today.London: Ken Booth dan Steve Smith, eds.

UNHCR. (2011). Refugee Protection: A Guide to International Refugee Law.UNHCR. (2012). The State of the World's Refugees 1997-1998.A Humanitarian Agenda.New York: Oxford University Press.

UNHCR. (2015). Pengenalan tentang Perlindungan Internasional: Melindungi Orang-Orang yang Menjadi Perhatian UNHCR. Switzerland: Komisariat Tinggi PBB untuk Urusan Pengungsi..

UNHCR. (2016). Pengenalan tentang Perlindungan Internasional: Melindungi Orang-Orang yang Menjadi Perhatian UNHCR.

Wu, Gung. (2017). Global History and Migration. Oxford: Wesview Press. 